\title{
Modification and comparison of three Gracilaria spp. agarose with methylation for promotion of its gelling properties
}

\author{
Yangyang $\mathrm{Gu}^{\dagger}$, Kit-Leong Cheong ${ }^{\dagger}$ and Hong Du ${ }^{*}$
}

\begin{abstract}
In order to improve the gelling properties of agarose, we modified it by methylation. The agarose was prepared from Gracilaria asiatica, G. bailinae, and G. lemaneiformis with alkaline, treated with diatomaceous earth and activated carbon, and anhydrous alcohol precipitation. The methylation reaction process of agarose was performed with dimethyl sulfate while the chemical structure of low-gelling temperature of agarose was also studied by ${ }^{13} \mathrm{C}-\mathrm{NMR}$ and FT-IR spectra. Results showed that the quality of agarose from G. asiatica is optimal. Its electroendosmosis is 0.116 , sulfate content is $0.128 \%$, and its gel strength $(1.5 \%, W / V)$ is $1024 \mathrm{~g} \mathrm{~cm}^{-2}$, like those of the Sigma product (A9539). The gelling temperature, melting temperature, and gel strength of the low-gelling temperature agarose is $28.3,67.0^{\circ} \mathrm{C}$, and $272.5 \mathrm{~g} \mathrm{~cm}^{-2}$, respectively. FT-IR Spectra and ${ }^{13} \mathrm{C}-\mathrm{NMR}$ spectra also showed that agarose was successfully methylated. Overall, this work suggests that low-gelling temperature agarose may have potential uses as an agar embedding material in various applications such as biomedicine, food, microbiology, and pharmaceutical.
\end{abstract}

Keywords: Agarose, Gracilaria, Low-gelling temperature agarose, Physico-chemical properties

\section{Introduction}

Agar, a mixture of cell-wall polysaccharides including agarose and agaropectin, can be extracted from various species of marine red algae (Rhodophyta) [1]. The predominant agar component, agarose, an electrically neutral polymer, is made up of the repeating unit of agarobiose disaccharide of a 3-O-linked $\beta$-D-galactopyranose residue, alternating with a 4- $O$-linked 3,6 anhydro- $\alpha-\mathrm{L}-$ galactopyranose in linear sequence [2]. The agaropectin is a heterogeneous mixture of smaller molecules that account for lesser amounts of agar. Further, agaropectin is not electrically neutral, due to heavy modifications of sulfate, pyruvate, and methyl side-groups; these chemical substituents are responsible for the varying gel properties of the polysaccharide in aqueous solutions. Due to its non-ionic nature, agarose as aqueous gel has been widely used as culture media and substrates for electrophoresis

\footnotetext{
*Correspondence: hdu@stu.edu.cn

${ }^{\dagger}$ Yangyang Gu and Kit-Leong Cheong contributed equally to this work Department of Biology, Guangdong Provincial Key Laboratory of Marine Biotechnology, STU-UNIVPM Joint Algal Research Center, College of Science, Shantou University, Shantou 515063, Guangdong, PR China
}

$[3,4]$. Agarose has been used as thickeners in foods, cosmetics, and other conventional uses $[5,6]$, and can be used for pharmaceutical and cell encapsulation $[7,8]$.

For all these applications, suitable gelling and melting temperatures of agarose are of particular importance. Biotechnological grade agarose typically has a gelling temperature of about $37^{\circ} \mathrm{C}$ and a melting temperature of above $70{ }^{\circ} \mathrm{C}$, which is not favorable for maintaining the activity or integrity of biological reagents. Therefore, we need a low agaropectin content of algae for the preparation of agarose, and via chemical modification to reduce its gelling temperature and obtain the low-gelling form. In general, Gelidium-extracted agar typically has better quality, such as higher gel strength, but the high cost plus the gradual exhaustion of natural prairies have prompted a search for alternative sources [9]. We need a kind of algae that can take Gelidium for the preparation of agarose. Gracilaria (Gracilariales, Rhodophyta), a cosmopolitan genus, has strong adaptability and high speed of growth, which has become one of our options. G. asiatica, G. bailinae, and G. lemaneiformis are rich species of Gracilaria algae. In recent years, the Gracilaria algae farming industry has 
developed, e.g., the cultivation area of G. lemaneiformis is more than 200,000 acres and production is over 150,000 tons (dried weight) per year in China, providing an excellent substitute for Gelidium agar in the industry [10]. However, the quality of agarose from Gracilaria species is low, due to high sulfate content. Treatment with sodium hydroxide converts L-galactose-6-sulfate to 3,6-anhydroL-galactose, and thus greatly improves agarose quality [11, 12]. High quality agarose is obtained by further purification such as isopropanol precipitation, ion-exchange chromatography, and size-exclusion chromatography $[13,14]$. Typically, when agarose concentration is $1.0 \%(w / v)$, high quality agarose has a gel strength of at least $750 \mathrm{~g} \mathrm{~cm}^{-2}$, a gelling temperature of $37{ }^{\circ} \mathrm{C}$, a melting temperature of $85^{\circ} \mathrm{C}$, a sulfate content of $0-0.15 \%(w / w)$, and an electroendosmosis (EEO) of 0.15 or less [15]. Gel properties include gelling temperature, gel melting temperature, and gel strength with different seaweed sources and extraction conditions [16]. It has also been found that gelling temperature can vary in modified agarose [17].

The aims of this study were to assess which species ( $G$. asiatica, G. bailinae, and G. lemaneiformis) were suitable for agarose preparation; this would involve alkaline treatment with anhydrous alcohol precipitation procedures to obtain good preparation conditions for low-gelling temperature agarose by methylation. Comparison was made of physico-chemical properties of agarose from seaweed to commercially available products of Sigma and Biowest. It might provide more information about FT-IR and ${ }^{13} \mathrm{C}$ NMR spectra related to agarose and low-gelling temperature agarose, and then obtaining the relationship between changes of physico-chemical properties (such as gelling temperature, melting temperature, sulfate content, and EEO) and their structure.

\section{Experimental \\ Materials}

Red algae Gracilaria (G. asiatica, G. bailinae, and G. lemaneiformis) were obtained from Chenghai district agar glue factory (Shantou, China). Specimens of Gracilaria were harvested in April (2013) in Nan'ao County $\left(23^{\circ} 28^{\prime} 46.23^{\prime \prime} \mathrm{N}\right.$ and $\left.117^{\circ} 06^{\prime} 24.58^{\prime \prime} \mathrm{E}\right)$ in Shantou, China. Three kinds of red algae Gracilaria were identified by a corresponding author. For the comparative study, Biowest agarose (Cat. NO. 111860) was purchased from GENE COMPANY LTD. (HK), Commercial agarose (no methylation) (Cat. NO. A9539), low-gelling temperature-agarose (GT: $29.5 \pm 1.0{ }^{\circ} \mathrm{C}$, MT: $65.0 \pm 0.9{ }^{\circ} \mathrm{C}$, GS: $266.8 \pm 5.2 \mathrm{~g} \mathrm{~cm}^{-2}$ ) (Cat. NO. A9414) while other chemicals were purchased from Sigma-Aldrich Co. LLC. (St. Louis, MO, USA).

\section{Agarose preparation}

Low grade agarose with the higher sulfate content was prepared according to the process specified in the patent [18]. Briefly, red algae Gracilaria was boiled in alkaline solution at $90{ }^{\circ} \mathrm{C}$ for $2 \mathrm{~h}$, filtered with diatomaceous earth and activated carbon; finally, agarose was dried in air, followed by more drying in the oven at $50{ }^{\circ} \mathrm{C}$ for $24 \mathrm{~h}$. Low grade agarose was further purified by using the anhydrous alcohol precipitation. To this end, low grade agarose was dissolved in deionized water $(1: 50 \mathrm{w} / \mathrm{v})$ and autoclaved for $1.5 \mathrm{~h}$ at $120{ }^{\circ} \mathrm{C}$. The solution was slowly cooled to about $40{ }^{\circ} \mathrm{C}$ with steady stirring. The solution was transferred into a beaker, and anhydrous alcohol (1:4 $v / v$ ) was added. After thorough mixing and standing for $12 \mathrm{~h}$ at room temperature, agarose was obtained by centrifugation at $10,000 \mathrm{rpm} \mathrm{min}{ }^{-1}$ at for $30 \mathrm{~min}$ at $25^{\circ} \mathrm{C}$, which was dried in the oven at $65^{\circ} \mathrm{C}$ for $12 \mathrm{~h}$ and ground.

\section{Agarose methylation}

Purified agarose $(2 \mathrm{~g})$ was boiled in deionized water $(100 \mathrm{~mL})$ for $1 \mathrm{~h}$ before adding $\mathrm{NaBH}_{4}(0.12 \mathrm{~g})$. The reaction mixture was incubated at $80{ }^{\circ} \mathrm{C}$ for 15 min with constant stirring. Next, $6.5 \mathrm{~mL} \mathrm{NaOH}\left(5 \mathrm{~mol} \mathrm{~L}^{-1}\right)$ and $2 \mathrm{~mL}$ DMS were added and incubated for $60 \mathrm{~min}$ at $78{ }^{\circ} \mathrm{C}$ with constant stirring (Fig. 1). After the reaction, the mixture was cooled to $60^{\circ} \mathrm{C}$ before being neutralized with $3 \mathrm{~mol} \mathrm{~L}^{-1}$ acetic acid. Methylated agarose was precipitated and dried, and is similar to the preparation of agarose.

\section{Physical properties}

Agarose was powdered and used for measurements of gel strength, gelling temperature, and melting temperature. Also, 1.5\% $(w / v)$ gel solution was prepared by dissolving agarose in deionized water in an autoclave at $120{ }^{\circ} \mathrm{C}$ for $1.5 \mathrm{~h}$. Gel strength was assessed with a Gel Tester (Kiya Seisakusho, Japan). Gelling and melting temperature were measured according to a previous report [19].

\section{Chemical properties}

Sulphate content was determined following the turbidrimetric method, reported by Dodgson and Price (1963) using $\mathrm{K}_{2} \mathrm{SO}_{4}$ as standard. EEO was determined following the modified procedures previously reported [20]. Agarose $(0.2 \mathrm{~g})$ was boiled in $\mathrm{pH} 8.6 \mathrm{TBE}$ buffer $(10 \mathrm{~mL})$. The standard test solution consisted of $40 \mathrm{mg} \mathrm{mL}^{-1}$ Dextran-700 and $5 \mathrm{mg} \mathrm{mL}^{-1}$ bovine serum albumin (BSA). The EEO standards were run at a constant voltage $(75 \mathrm{~V})$ for $3 \mathrm{~h}$. EEO (mr) in agarose gel was calculated with the equation: $\mathrm{mr}=\mathrm{OD} /(\mathrm{OD}+\mathrm{OA})$, and $\mathrm{OD}$ and $\mathrm{OA}$ representing the distance from origin of dextran and albumin. 


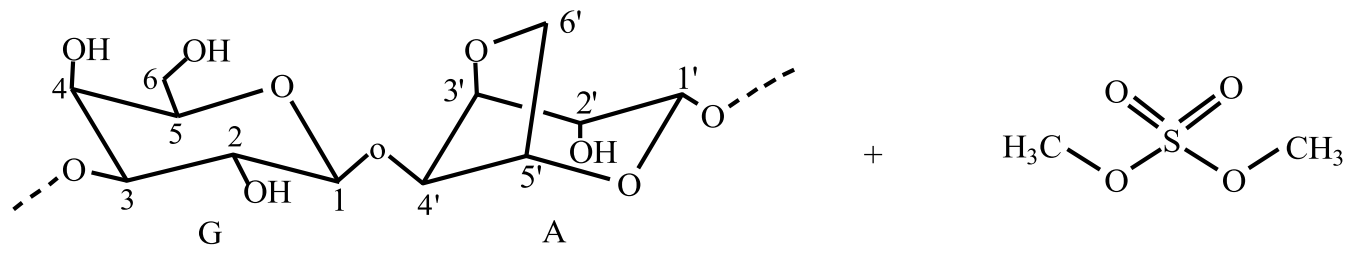

Native agarose

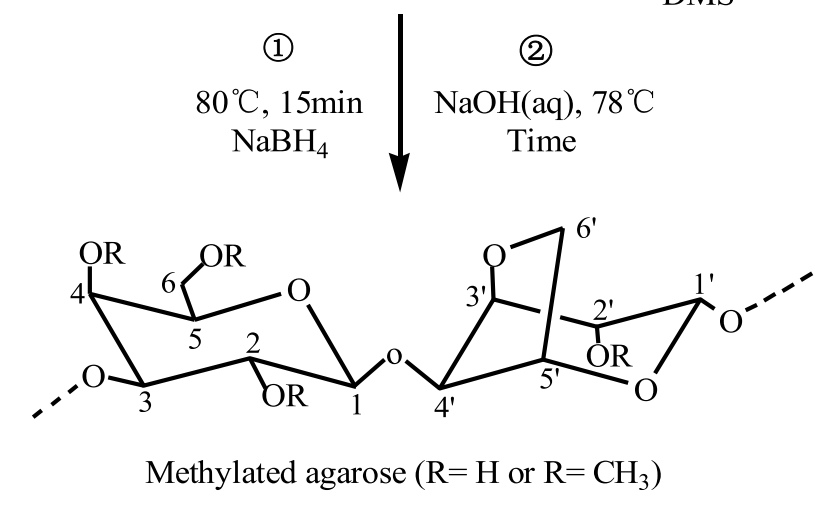

DMS

Fig. 1 Synthetic routes of methylated agarose

\section{DNA electrophoresis}

Goldview DNA stain (Takara, China) was loaded into 1\% agarose gel in TAE buffer and run at $110 \mathrm{~V}$ for $50 \mathrm{~min}$ in a standard horizontal electrophoresis unit. DNA was observed under UV illumination, and images were collected immediately after electrophoresis.

\section{FT-IR spectra}

FT-IR spectra of agarose and low-gelling temperatureagarose were recorded with a FT-IR Spectrometer (Nicolet, Rhinelander, WI, USA), in the $4000-400 \mathrm{~cm}^{-1}$ range with a resolution of $2 \mathrm{~cm}^{-1}$ using $\mathrm{KBr}$ pellets.

\section{${ }^{13}$ C-NMR}

Noise-decoupled ${ }^{13} \mathrm{C}$-NMR spectra of agarose and low-gelling temperature agarose were recorded with a Superconducting Fourier Transform Nuclear Magnetic Resonance Spectrometer (Varian INOVA 500NB, Falls Church, VA, USA) at $125 \mathrm{MHz}$. The samples were dissolved in $\mathrm{D}_{2} \mathrm{O}\left(50 \mathrm{mg} \mathrm{mL}^{-1}\right)$ and analyzed with a $10 \mathrm{~mm}$ inverse probe. Spectra were recorded at $70{ }^{\circ} \mathrm{C}$ with pulse duration of $15 \mu \mathrm{s}$, acquisition time $0.4499 \mathrm{~s}$, relaxation delay $1.55 \mathrm{~s}$, spectral width $29.76 \mathrm{kHz}, 3700-3900$ scans, using DMSO as the internal standard (ca. $39.5 \mathrm{ppm}$ ); the sample was scanned 3700-3900 times.

\section{Results}

\section{Comparison of agar from Gracilaria}

The physico-chemical properties of agarose from G. asiatica, G. bailinae, and G. lemaneiformis were measured and compared with those of Bio-west (Logan, UT, USA) and Sigma (St. Louis, MO, USA) (Table 1), showing that gel strength of low-grade agarose was above $750 \mathrm{~g} \mathrm{~cm}^{-2}$, which was close to Biowest agarose. Sulfate content and electroendosmosis of it was higher than Biowest and Sigma, such that alkaline hydrolysis treatment cannot completely remove negative charge groups.

After treating with anhydrous alcohol, sulfate content and electroendosmosis decreased while gel strength increased in purified agarose (Table 1). Agarose from G. asiatica showed the greatest improvement for these parameters after alcohol treatment; however, no significant difference in gelling and melting temperatures ( $p>0.05)$ was found. Gel strength of purified agarose from $G$. asiatica $\left(1024 \pm 16.8 \mathrm{~g} \mathrm{~cm}^{-2}\right)$ was higher than that of Biowest agarose $\left(878 \pm 18.1 \mathrm{~g} \mathrm{~cm}^{-2}\right)$, but it was lower compared Sigma agarose $\left(1127 \pm 23.6 \mathrm{~g} \mathrm{~cm}^{-2}\right)$. The sulphate content $(0.13 \pm 0.02 \%)$ and EEO $(0.12 \pm 0.002)$ of purified agarose from $G$. asiatica were lower than that of Biowest agarose. The quality of prepared agarose is higher than reported results [21]. Consistently, a DNA electrophoresis experiment showed that eight DNA bands were clearly distinguishable from agarose gel prepared (Fig. 2), indicating that G. asiatica agarose gel had higher intensity and better DNA detection sensitivity than agarose from G. lemaneiformis and G. Bailinae.

\section{Modification of agarose with methylation}

To optimize the methylation condition, $\mathrm{NaOH}$ solution in different quantities $(5.0-15.5 \mathrm{~mL})$ and $2 \mathrm{~mL}$ of DMS 
Table 1 Physico-chemical properties of agaroses from G. asiatica, G. bailinae, G. lemaneiformis, Sigma, and Biowest

\begin{tabular}{|c|c|c|c|c|c|c|c|c|c|c|}
\hline \multirow[t]{2}{*}{ Agarose } & \multicolumn{2}{|l|}{$\mathrm{GT}^{\mathrm{a}}\left({ }^{\circ} \mathrm{C}\right)$} & \multicolumn{2}{|l|}{ MT $\left({ }^{\circ} \mathrm{C}\right)$} & \multicolumn{2}{|l|}{$\mathrm{GS}\left(\mathrm{g} \mathrm{cm}^{-2}\right)$} & \multicolumn{2}{|l|}{ SC (\%) } & \multicolumn{2}{|l|}{ EEO } \\
\hline & $\mathrm{C}$ & $\mathbf{T}$ & C & $\mathbf{T}$ & $\mathrm{C}$ & $\mathbf{T}$ & $\mathrm{C}$ & $\mathbf{T}$ & $C$ & $\mathbf{T}$ \\
\hline G. asiatica & $38 \pm 1.2$ & $37 \pm 0.3$ & $88 \pm 0.8$ & $88 \pm 1.5$ & $872 \pm 15.8$ & $1024 \pm 17.0^{* *}$ & $0.17 \pm 0.01$ & $0.13 \pm 0.02^{*}$ & $0.16 \pm 0.005$ & $0.12 \pm 0.002^{*}$ \\
\hline G. bailinae & $39 \pm 0.8$ & $38 \pm 0.3$ & $89 \pm 1.0$ & $89 \pm 0.5$ & $879 \pm 26.9$ & $1003 \pm 13.6^{* *}$ & $0.20 \pm 0.01$ & $0.17 \pm 0.02^{*}$ & $0.18 \pm 0.004$ & $0.16 \pm 0.003$ \\
\hline G. lemaneiformis & $37 \pm 0.8$ & $37 \pm 0.3$ & $89 \pm 1.0$ & $92 \pm 0.8$ & $896 \pm 23.2$ & $1008 \pm 21.6^{* *}$ & $0.18 \pm 0.02$ & $0.15 \pm 0.01^{*}$ & $0.17 \pm 0.004$ & $0.15 \pm 0.003$ \\
\hline Biowest & $38 \pm 0.8$ & & $93 \pm 1.9$ & & $878 \pm 18.1$ & & $0.15 \pm 0.01$ & & $0.13 \pm 0.002$ & \\
\hline Sigma & $37 \pm 0.9$ & & $92 \pm 0.6$ & & $1127 \pm 23.6$ & & $0.12 \pm 0.01$ & & $0.11 \pm 0.003$ & \\
\hline
\end{tabular}

Results are expressed as mean \pm standard deviation $(n=3)$. Statistically different ${ }^{*} p<0.05,{ }^{* *} p<0.01$ vs control

GT gelling temperature, MT melting temperature, GS gel strength, SC sulfate content, EEO electroendosmosis, $C$ control group, $T$ treatment group

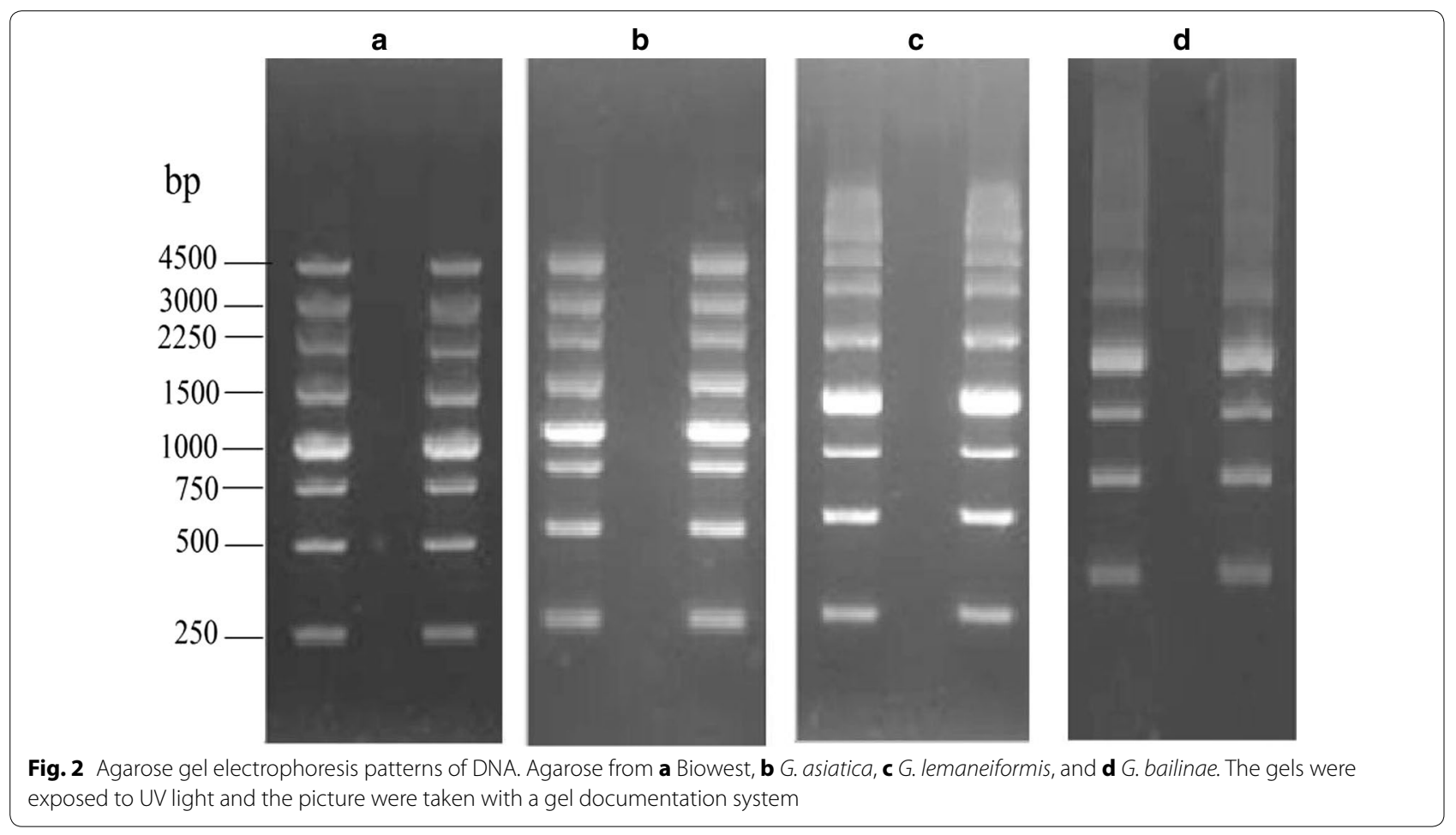

were added to the reaction for $75 \mathrm{~min}$. The gelling and melting temperatures and gel strength were positively correlated with the amount of added $\mathrm{NaOH}$ (Fig. 3); at $6.5 \mathrm{~mL} \mathrm{NaOH}$, the gelling temperature $\left(27^{\circ} \mathrm{C}\right)$ and gel strength $\left(288 \mathrm{~g} \mathrm{~cm}^{-2}\right)$ were $2.5^{\circ} \mathrm{C}$ lower and $21.2 \mathrm{~g} \mathrm{~cm}^{-2}$ higher, respectively, than Sigma low-gelling temperature agarose (A9414).

DMS in different quantities $(1-3 \mathrm{~mL})$ and $6.5 \mathrm{~mL}$ of $\mathrm{NaOH}$ were added to the reaction for $75 \mathrm{~min}$. The gelling temperatures, melting temperature, and gel strength were negatively correlated to the added DMS (Fig. 4), and at $2.0 \mathrm{~mL}$ DMS, the gelling temperature $\left(27^{\circ} \mathrm{C}\right)$, melting temperature $\left(66.9^{\circ} \mathrm{C}\right)$, and gel strength $\left(276 \mathrm{~g} \mathrm{~cm}^{-2}\right)$ were superior to agarose produced at 1 or $3 \mathrm{~mL}$ of DMS.
We tested the reaction time from 30 to $105 \mathrm{~min}$ (Fig. 5). At $60 \mathrm{~min}$, the gelling temperature and melting temperature declined to 28 and $67^{\circ} \mathrm{C}$, respectively. The gel strength was $272 \mathrm{~g} \mathrm{~cm}^{-2}$ and stronger than Sigma lowgelling temperature agarose. The reaction with a recipe of $2 \mathrm{~g}$ agarose, $6.5 \mathrm{~mL} \mathrm{NaOH}\left(5 \mathrm{~mol} \mathrm{~L}^{-1}\right), 2 \mathrm{~mL}$ DMS, and a reaction time of $60 \mathrm{~min}$ produces the most desirable product.

\section{Chemical properties of methylated agarose}

FT-IR spectra (Fig. 6) shows no absorption was found in the region of $850-820 \mathrm{~cm}^{-1}$, corresponding to $\mathrm{C}-\mathrm{O}-\mathrm{S}$ stretching, and indicating the absence of $\mathrm{C} 4$, and C6-sulphate in the galactopyranose moiety. The peak at 

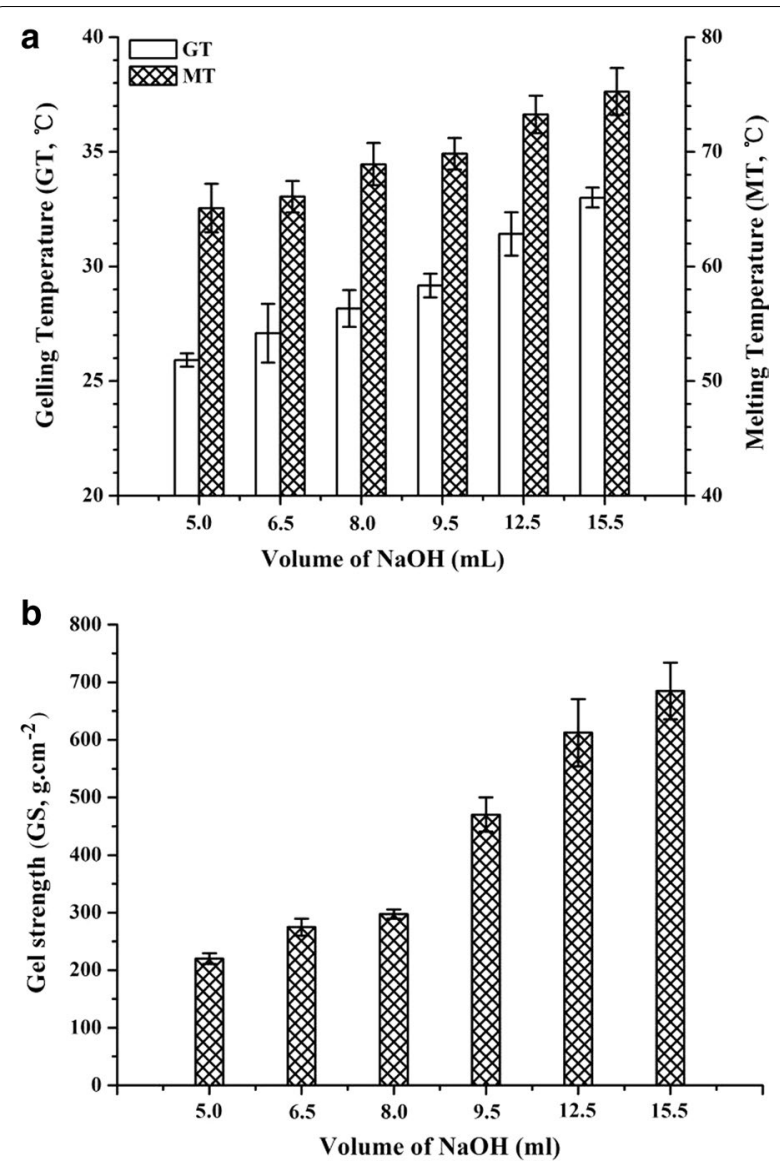

Fig. 3 Effect of $\mathrm{NaOH}$ aqueous on a gelling temperature, melting temperature, and $\mathbf{b}$ gel strength of agarose. Values are mean $\pm \operatorname{SD}(n=3)$

$820-772 \mathrm{~cm}^{-1}$ was sharper than Biowest agarose, demonstrating that agarose from G. asiatica had a higher purity. The peak at $930 \mathrm{~cm}^{-1}$ was indicative of 3,6-AG residues being sharper and deeper than Biowest agarose, suggesting that agarose from G. asiatica had a higher purity, and that negatively charged groups of agar polysaccharides were effectively removed. The huge peak at $3450 \mathrm{~cm}^{-1}$ indicated that agarose had a large number of hydroxyl groups. The FT-IR spectra of metylated agarose indicated they have the same carbon skeleton structure with the purified agarose. The spectra experienced a significant change with the peak at $1650 \mathrm{~cm}^{-1}$ splitting into two peaks at 1650 and $1566 \mathrm{~cm}^{-1}$, and increasing to about $820 \mathrm{~cm}^{-1}$ in the methylated agarose. The FT-IR spectra of purified agarose from G. asiatica were in agreement with Biowest agarose.

The ${ }^{13} \mathrm{C}$-NMR spectra of agarose samples were presented in Fig. 7 and Table 2. The chemical shifts of the 12 carbon atoms of the disaccharide repeating units of agaroses were comparable with the reported Sigma agarose
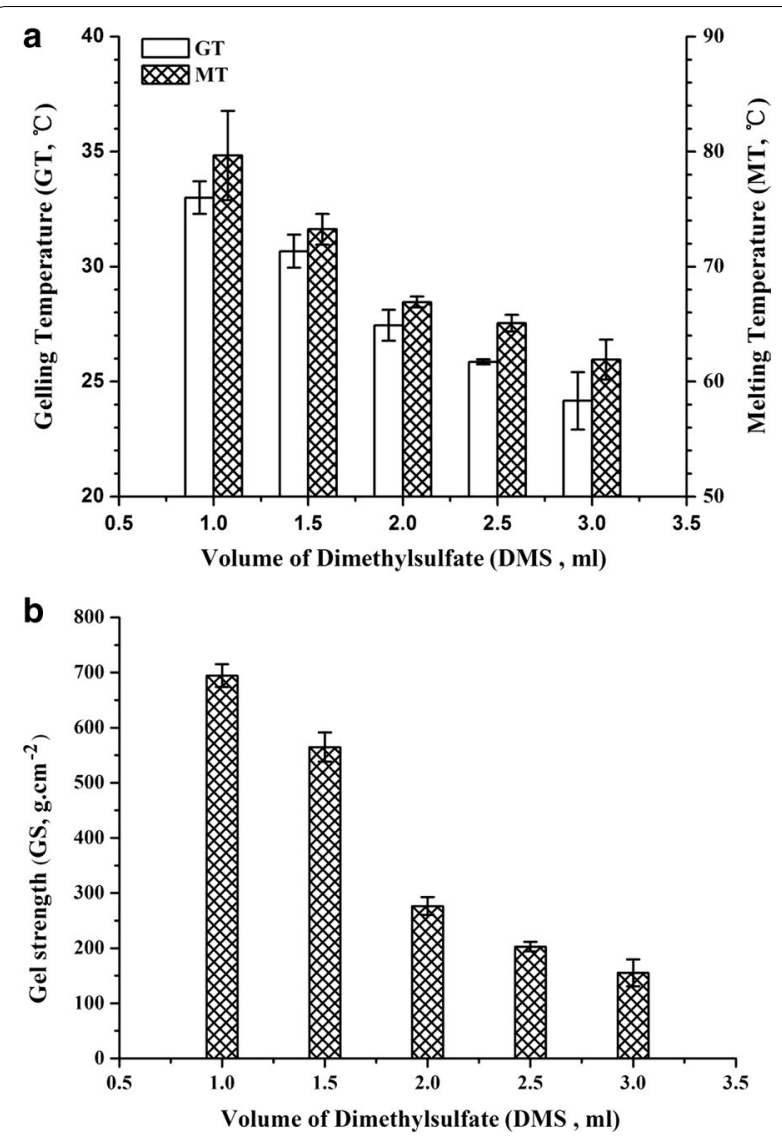

Fig. 4 Effect of DMS aqueous on a gelling temperature, melting temperature, and $\mathbf{b}$ gel strength of agarose. Values are mean $\pm S D(n=3)$

in the literature [22] (Table 2). The signals at 102.45, $70.28,82.25,68.79,75.42$, and $61.45 \mathrm{ppm}$ corresponded to the 3-linked units, while the signals at $98.38,69.88$, $80.14,77.41,75.66$, and $69.66 \mathrm{ppm}$ corresponded to the 4-linked units. Purified agarose from G. asiatica had identical spectra as the agarose from Sigma, while methylated agarose had two additional large $-\mathrm{OCH}_{3}$ peaks at 59.2 and $56.01 \mathrm{ppm}$, with some other new peaks at 98.95 , 81.72, 79.02, and $78.71 \mathrm{ppm}$, showing that NMR spectra from carbon atoms are sensitive to the methylation. Methylation caused the changes of the chemical shift of the adjacent carbon atoms, the effect being from 0.08 to $0.20 \mathrm{ppm}$ (Table 2). All of these results suggested that methylated agarose was successfully synthesized.

\section{Discussion}

High quality agarose can be obtained with $\mathrm{NaOH}$ treatment and anhydrous alcohol precipitation procedures to remove sulfate and pyruvate residues. Agarose prepared from Gracilaria dura by alkali treatment has a residual sulfate content of $0.25 \%$ [22]. Further treatment with isopropyl alcohol precipitation reduces the sulfate content 

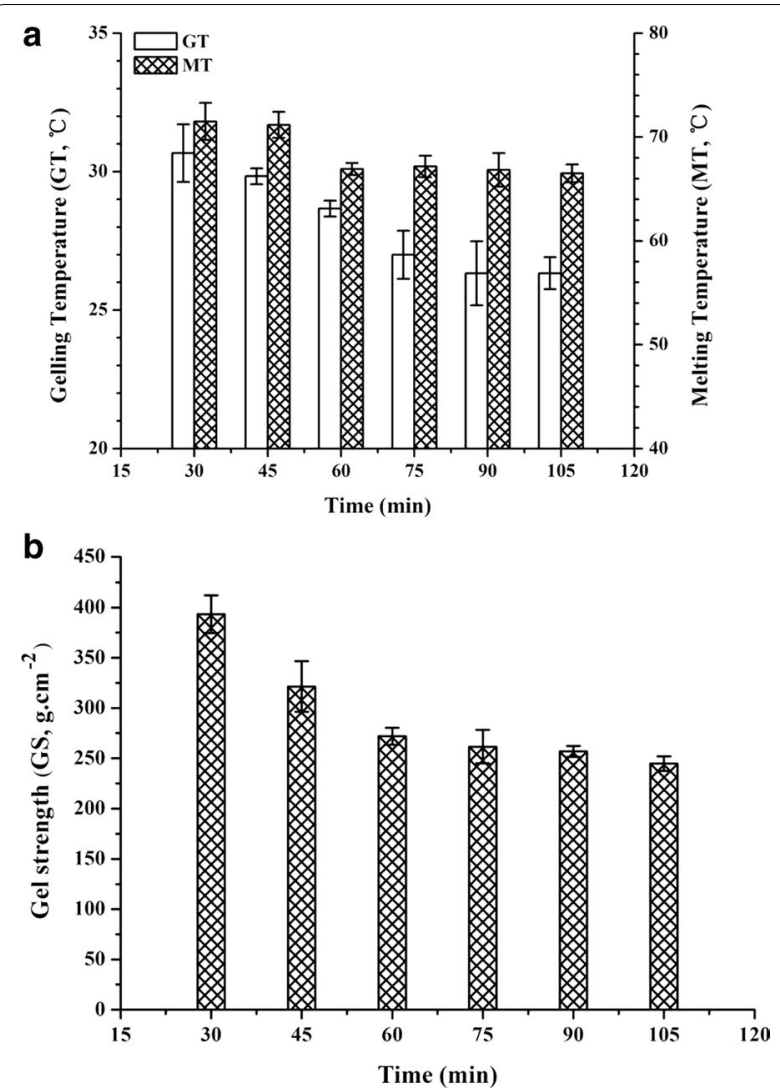

Fig. 5 Effect of reaction time on a gelling temperature, melting temperature, and $\mathbf{b}$ gel strength of agarose. Values are mean $\pm \operatorname{SD}(n=3)$

to $0.14 \%$ in agarose prepared from G. amansi [1]. In this study, we used the anhydrous alcohol precipitation method, as it is a more environmentally-friendly process; anhydrous alcohol can be recycled during the industrial agarose preparation.

The method of $\mathrm{NaOH}$ treatment and anhydrous alcohol precipitation was applied to agarose preparation from Gracilaria (G. asiatica, G. bailinae, and G. lemaneiformis). G. asiatica had more carbohydrates and less ash than G. lemaneiformis (Table 3), which may explain the higher quality of agarose prepared from G. asiatica. The molecular weight of agarose, with none of the other substituents, showed a gel strength related to the content of the sulfate residue, reduced the amount of sulfate residue, and increased the purity of agarose and the content of 3,6-anhydrogalactose [16]. The content of 3,6-anhydrogalactose related to the gel strength, the higher content of the 3,6-anhydrogalactose, and the greater the gel strength. However, the gel strength of agarose among the tested species (G. asiatica, G. bailinae, G. lemaneiformis) was not significantly different. The literature had reported that different growth environments, as well as the content of agaropectin being different, included molecular weights of different agarose being different as well [22]. These factors would affect the gel strength, as the lower the molecular weight of agarose, the lower the gel strength. Changes of electroendosmosis were in conformity with the changes of sulfate residue present on the agarose, but it was necessary to clarify electroendosmosis reduction, not only related to the sulfate residue content, but also to the loss of agar of other negatively charged groups.

Based on the best reaction conditions, the gelling and melting temperature of methylated agarose is lower and higher than Sigma's product (A9414), respectively. This is due to $-\mathrm{OH}$ of Sigma's product being modified by hydroxyethyl. To our knowledge, the optimization of agarose from G. asiatica methylated by using DMS has not been reported. By using less $\mathrm{NaOH}$, DMS, and time during the preparation of methylated agarose, industry operation costs can be reduced. This methylation method of agarose with DMS is safe, simple, convenient, and suitable for industrial application.

In FT-IR spectra of both the prepared agarose from G. asiatica and the Biowest agarose, a clear peak at about $3450 \mathrm{~cm}^{-1}$ corresponding to $-\mathrm{OH}$ stretching was detected. However, the hydroxy peak of methylated agarose at $\sim 3450 \mathrm{~cm}^{-1}$ did not apparently disappear or decrease, and the $-\mathrm{OCH}_{3}$ peak at $2950 \mathrm{~cm}^{-1}$ was not an obvious enhancement, indicating $-\mathrm{OH}$ of agarose was not completely methylated. Further, $-\mathrm{CH}_{3}$ can be directly connected to pyranoses of agarose, leading to the $\mathrm{C}-\mathrm{O}$ stretch vibration peak split (the peak at $1650 \mathrm{~cm}^{-1}$ splits into two peaks at 1650 and $\left.1566 \mathrm{~cm}^{-1}\right) \cdot{ }^{13} \mathrm{C}-\mathrm{NMR}$ spectra of prepared agarose only have 12 signals of chemical shift, no chemical shift of carbon atomic agaropectin $(101.6,69.3,71.2,79.1,70.2$, and $67.9 \mathrm{ppm})$ and starch polysaccharide $(100.7,72.7,74.3,78.7,72.5$, and $62.2 \mathrm{ppm})$. These results indicated that the agaropectin and starch polysaccharide in the agar have been removed [23]. In the ${ }^{13} \mathrm{C}-\mathrm{NMR}$ spectra of methylated agarose, three carbon atoms A1 (98.46 ppm), G3 (82.20 ppm) and A4 (77.51 ppm) appear as distinct small peak signals, possibly due to the presence of $-\mathrm{OCH}_{3}$ groups in methylated agarose; this results in anisotropy around the three carbons. FT-IR and ${ }^{13} \mathrm{C}$-NMR spectra correspond to changes of physical properties of methylated agarose.

\section{Conclusion}

In this study, electroendosmosis of preparation agarose from G. asiatica was 0.12 , sulfate content was $0.13 \%$ and gel strength $(1.5 \%, w / v)$ was $1024 \mathrm{~g} \mathrm{~cm}^{-2}$. Low-gelling 

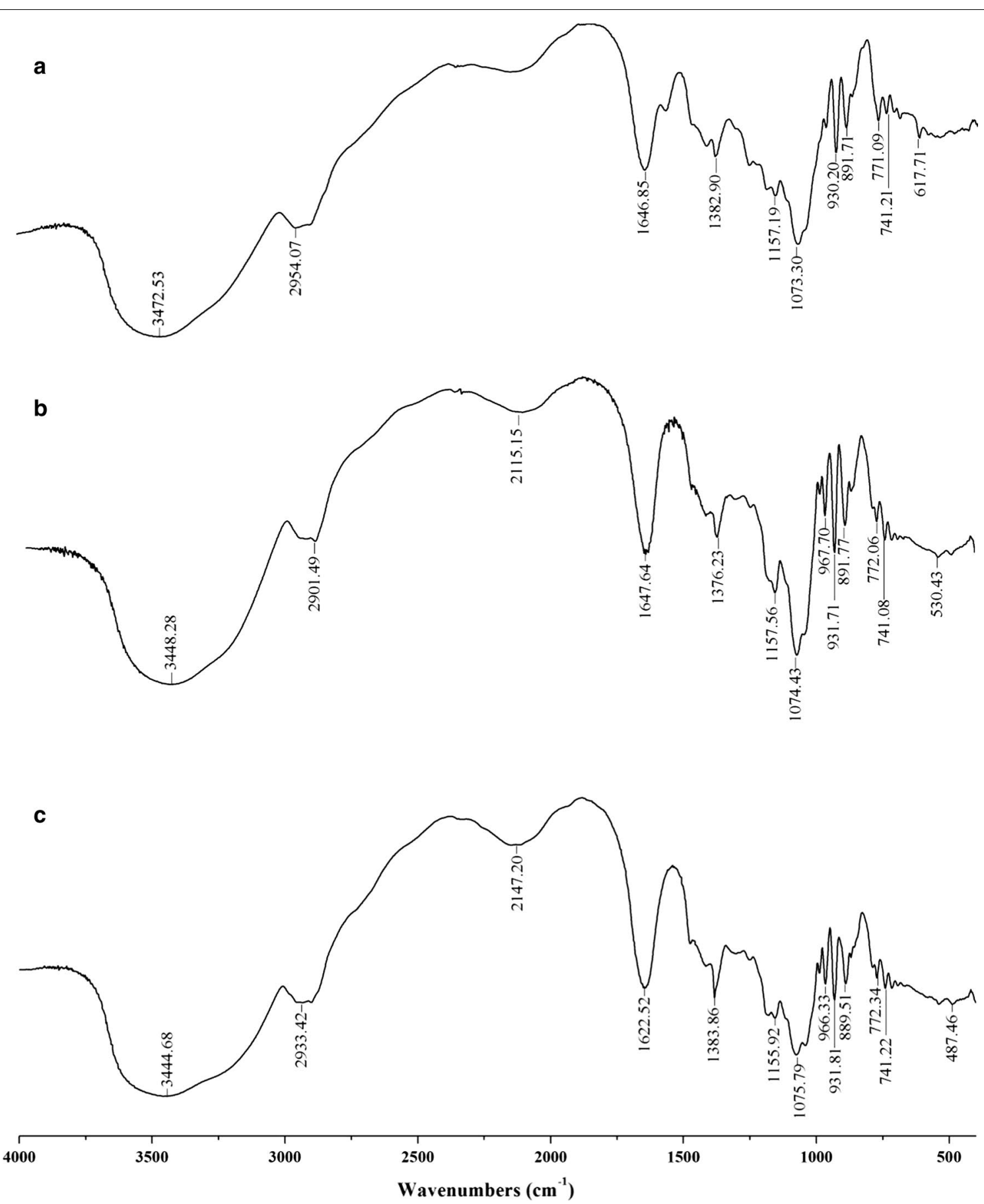

Fig. 6 Fourier transforms infrared spectra of $\mathbf{a}$ G. asiatica agarose, b G. asiatica methylated agarose, and $\mathbf{c}$ Biowest agarose

temperature agarose was prepared successfully. The gelling temperature, melting temperature, and gel strength of the low-gelling temperature was $28.3,67.0{ }^{\circ} \mathrm{C}$, and $272.5 \mathrm{~g} \mathrm{~cm}^{-2}$, respectively. FT-IR Spectra showed the peak of methylated agarose at around $1650 \mathrm{~cm}^{-1}$ split into 1650 and $1566 \mathrm{~cm}^{-1}$ with two peaks. ${ }^{13} \mathrm{C}$-NMR spectra of methylated agarose had two clear signals of $-\mathrm{OCH}_{3}$ at 59.38 and $56.01 \mathrm{ppm}$. G. asiatica is more appropriate 
$\mathbf{a}$

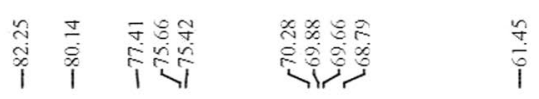

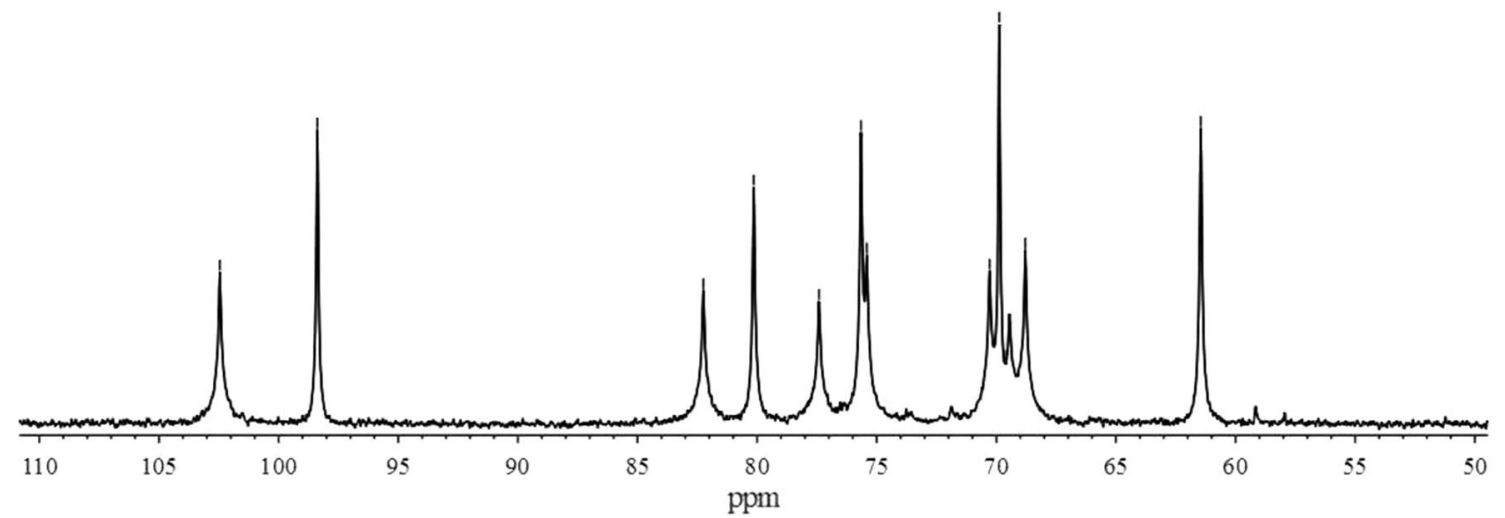

b
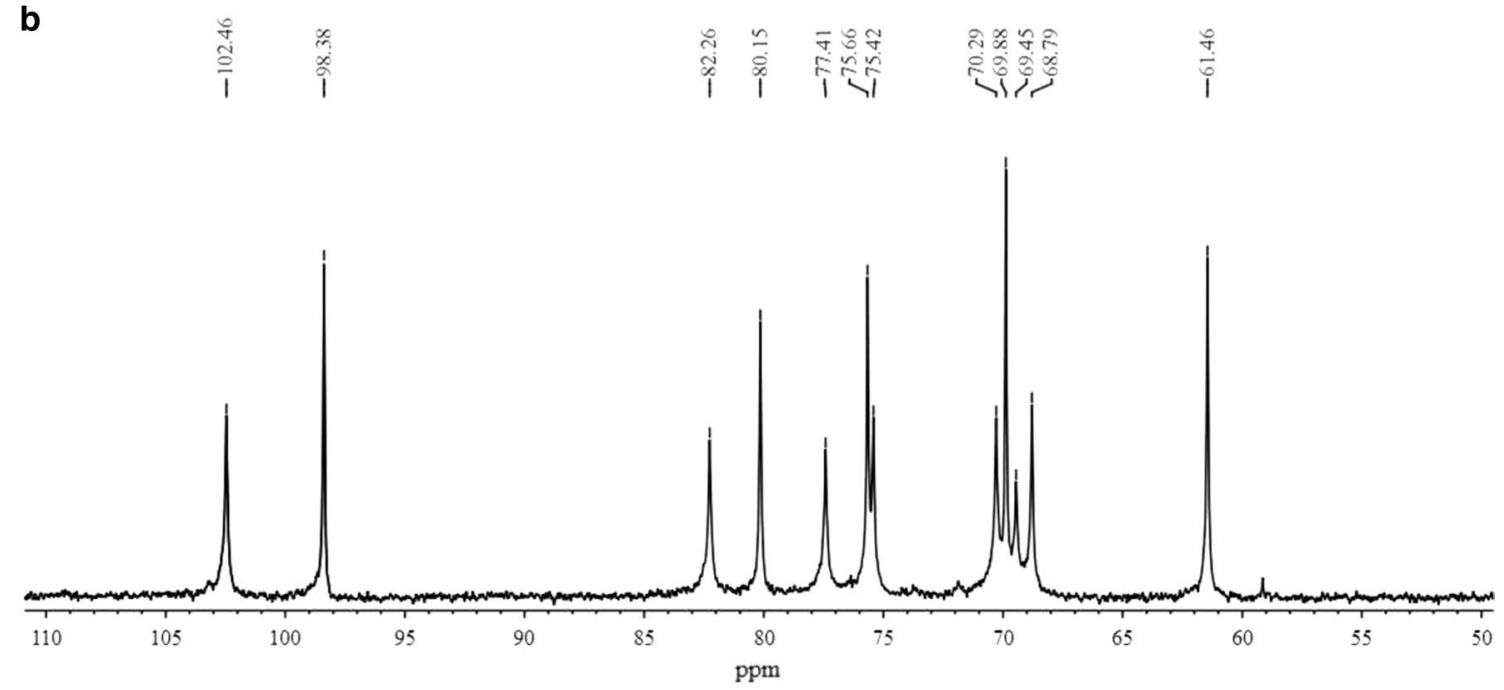

C
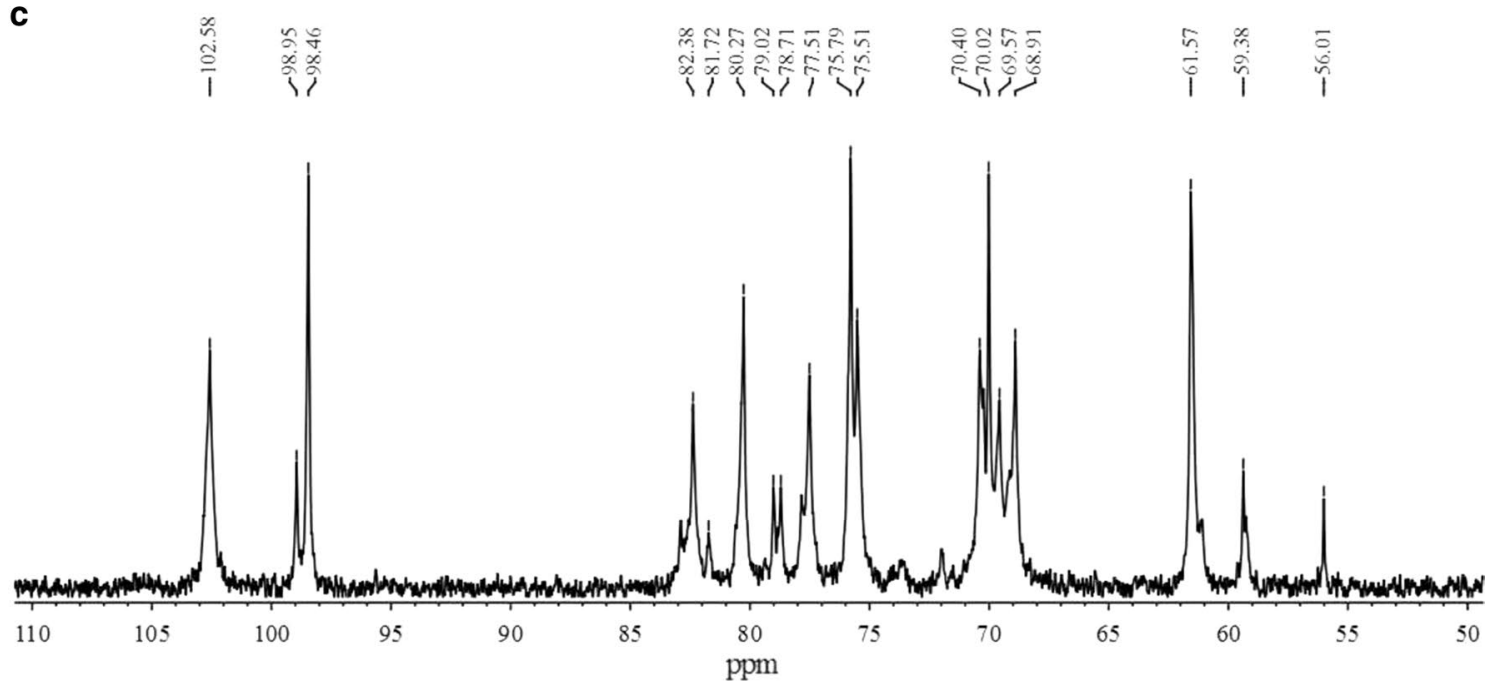

Fig. $7{ }^{13} \mathrm{C}-\mathrm{NMR}$ spectra of $\mathbf{a}$ G. asiatica agarose, $\mathbf{b}$ G. asiatica methylated agarose, and $\mathbf{c}$ Biowest agarose 
Table $2{ }^{13} \mathrm{C}$-NMR chemical shift of methylated agarose from G. asiatica and agarose from G. asiatica, Biowest, and Sigma

\begin{tabular}{|c|c|c|c|c|c|c|c|c|}
\hline \multirow[t]{2}{*}{ Agarose } & \multirow[t]{2}{*}{ Unit } & \multicolumn{7}{|c|}{${ }^{13} \mathrm{C}$ chemical shifts (ppm) } \\
\hline & & $\mathrm{C} 1$ & $\mathrm{C} 2$ & C3 & C4 & C5 & $\mathrm{C6}$ & $-\mathrm{OCH}_{3}$ \\
\hline \multirow[t]{2}{*}{ G. asiatica } & G & 102.45 & 70.28 & 82.25 & 68.79 & 75.42 & 61.45 & - \\
\hline & A & 98.38 & 69.88 & 80.14 & 77.41 & 75.66 & 69.66 & \\
\hline \multirow[t]{2}{*}{ G. asiatica (methylated) } & G & 102.58 & 70.40 & 82.38 & 68.91 & 75.51 & 61.57 & $59.38,56.01$ \\
\hline & A & 98.46 & 70.02 & 80.27 & 77.51 & 75.79 & 69.57 & \\
\hline \multirow[t]{2}{*}{ Biowest } & G & 102.46 & 70.29 & 82.26 & 68.79 & 75.42 & 61.46 & - \\
\hline & A & 98.38 & 69.88 & 80.15 & 77.41 & 75.66 & 69.45 & \\
\hline \multirow[t]{2}{*}{ Sigma } & G & 102.23 & 70.00 & 81.96 & 68.49 & 75.10 & 61.16 & - \\
\hline & A & 97.92 & 69.75 & 79.91 & 77.03 & 75.40 & 69.14 & \\
\hline
\end{tabular}

Table 3 Determination and comparison of the proximate composition between G. asiatica and G. lemaneiformis

\begin{tabular}{llllll}
\hline Species & \multicolumn{3}{l}{ Content (\%, dry weight) } & & \\
\cline { 2 - 6 } & $\begin{array}{l}\text { Crude } \\
\text { protein }\end{array}$ & $\begin{array}{l}\text { Carbohy- } \\
\text { drate }\end{array}$ & Crude fat & $\begin{array}{l}\text { Crude } \\
\text { fiber }\end{array}$ & Ash \\
\hline $\begin{array}{l}\text { G. asiatica } \\
\text { G. lemanei- } \\
\text { formis }\end{array}$ & 18.6 & 61.8 & 0.4 & 6.2 & 13.0 \\
\hline
\end{tabular}

for agarose preparation, as methylated agarose also has good features. This methylated agarose is beneficial for the future application in biomedical, food, microbiology and pharmaceutical areas.

\section{Authors' contributions}

HD designed the study, participated in discussing the results, and revised the manuscript. YG and KLC performed the assays and prepared the manuscript. All authors read and approved the final manuscript.

\section{Competing interests}

The authors declare that they have no competing interests.

\section{Funding}

This work was financial supported by the National High Technology Research and Development Program of China (Grant No. 2012AA10A411), The Chinese Academy of Sciences and Comprehensive Strategy Cooperation Projects in Guangdong Province (Grant No. 2011 A090100040) and the National Natural Science Foundation of China (Grant No. 31000189).

\section{Publisher's Note}

Springer Nature remains neutral with regard to jurisdictional claims in published maps and institutional affiliations.

Received: 21 July 2017 Accepted: 9 October 2017

Published online: 16 October 2017

\section{References}

1. Wang T-P, Chang L-L, Chang S-N, Wang E-C, Hwang L-C, Chen Y-H, Wang Y-M (2012) Successful preparation and characterization of biotechnological grade agarose from indigenous Gelidium amansii of Taiwan. Process Biochem 47:550-554
2. Zhou C, Yu X, Zhang Y, He R, Ma H (2012) Ultrasonic degradation, purification and analysis of structure and antioxidant activity of polysaccharide from Porphyra yezoensis Udea. Carbohydr Polym 87:2046-2051

3. Bhilocha S, Amin R, Pandya M, Yuan H, Tank M, LoBello J, Shytuhina A, Wang W, Wisniewski H-G, de la Motte C, Cowman MK (2011) Agarose and polyacrylamide gel electrophoresis methods for molecular mass analysis of 5- to 500-kDa hyaluronan. Anal Biochem 417:41-49

4. Lee PY, Costumbrado J, Hsu C-Y, Kim YH (2012) Agarose gel electrophoresis for the separation of DNA fragments. JOVE-J Vis Exp 1:e3923

5. Wang H-MD, Chen C-C, Huynh P, Chang J-S (2015) Exploring the potential of using algae in cosmetics. Bioresour Technol 184:355-362

6. Yun EJ, Choi I-G, Kim KH (2015) Red macroalgae as a sustainable resource for bio-based products. Trends Biotechnol 33:247-249

7. Suleria H, Osborne S, Masci P, Gobe G (2015) Marine-based nutraceuticals: an innovative trend in the food and supplement industries. Mar Drugs 13:6336

8. Banerjee S, Bhattacharya S (2012) Food gels: gelling process and new applications. Crit Rev Food Sci Nutr 52:334

9. Sousa AMM, Alves VD, Morais S, Delerue-Matos C, Gonçalves MP (2010) Agar extraction from integrated multitrophic aquacultured Gracilaria vermiculophylla: evaluation of a microwave-assisted process using response surface methodology. Bioresour Technol 101:3258-3267

10. Qi Z, Liu H, Li B, Mao Y, Jiang Z, Zhang J, Fang J (2010) Suitability of two seaweeds, Gracilaria lemaneiformis and Sargassum pallidum, as feed for the abalone Haliotis discus hannai Ino. Aquaculture 300:189-193

11. Yarnpakdee S, Benjakul S, Kingwascharapong P (2015) Physico-chemical and gel properties of agar from Gracilaria tenuistipitata from the lake of Songkhla, Thailand. Food Hydrocolloids 51:217-226

12. Lee W-K, Namasivayam P, Ho C-L (2014) Effects of sulfate starvation on agar polysaccharides of Gracilaria species (Gracilariaceae, Rhodophyta) from Morib, Malaysia. J Appl Phycol 26:1791-1799

13. Souza BWS, Cerqueira MA, Bourbon Al, Pinheiro AC, Martins JT, Teixeira JA, Coimbra MA, Vicente AA (2012) Chemical characterization and antioxidant activity of sulfated polysaccharide from the red seaweed Gracilaria birdiae. Food Hydrocoll 27:287-292

14. Barros FCN, da Silva DC, Sombra VG, Maciel JS, Feitosa JPA, Freitas ALP, de Paula RCM (2013) Structural characterization of polysaccharide obtained from red seaweed Gracilaria caudata (J Agardh). Carbohydr Polym 92:598-603

15. Armisen R (1995) World-wide use and importance of Gracilaria. J Appl Phycol 7:231

16. Freile-Pelegrín Y, Murano E (2005) Agars from three species of Gracilaria (Rhodophyta) from Yucatán Peninsula. Bioresour Technol 96:295-302

17. Wang X, Duan D, Xu J, Gao X, Fu X (2015) Characterization of a novel alkaline arylsulfatase from Marinomonas sp. FW-1 and its application in the desulfation of red seaweed agar. J Ind Microbiol Biotechnol 42:1353-1362

18. Siddhanta AK, Meena R, Prasad K, Ramavat BK, Ghosh PK, Eswaran K, Thiruppathi S, Mantri VA (2005) Cost-effective process for preparing agarose from Gracilaria spp. United States patent application US $10 / 858,599$ 
19. Arvizu-Higuera DL, Rodríguez-Montesinos YE, Murillo-Álvarez Jl, MuñozOchoa M, Hernández-Carmona G (2008) Effect of alkali treatment time and extraction time on agar from Gracilaria vermiculophylla. J Appl Phycol 20:515-519

20. Guiseley K, Kirkpatrick FH, Nochumson S, Provonchee R (1991) High gel strength low electroendosmosis agarose. United States patent US 4,983,268

21. Li H, Yu X, Jin Y, Zhang W, Liu Y (2008) Development of an eco-friendly agar extraction technique from the red seaweed Gracilaria lemaneiformis. Bioresour Technol 99:3301-3305
22. Meena R, Siddhanta AK, Prasad K, Ramavat BK, Eswaran K, Thiruppathi S Ganesan M, Mantri VA, Rao PVS (2007) Preparation, characterization and benchmarking of agarose from Gracilaria dura of Indian waters. Carbohydr Polym 69:179-188

23. Rodríguez MC, Matulewicz MC, Noseda MD, Ducatti DRB, Leonardi PI (2009) Agar from Gracilaria gracilis (Gracilariales, Rhodophyta) of the Patagonic coast of Argentina-Content, structure and physical properties. Bioresour Technol 100:1435-1441

\section{Submit your manuscript to a SpringerOpen ${ }^{\odot}$ journal and benefit from:}

- Convenient online submission

- Rigorous peer review

- Open access: articles freely available online

- High visibility within the field

- Retaining the copyright to your article

Submit your next manuscript at $\boldsymbol{\nabla}$ springeropen.com 